though it is thought unlikely that the loss of mobility led to any undue change in the rate of bone resorption during dialysis in the present study. All subjects were treated as outpatients and between treatments carried out a near-normal daily activity.

Despite the possibility that these factors influence calcium metabolism and thereby affect direct measurements of the bone, our results indicated a gradual loss of bone with time. The loss was greater after peritoneal dialysis than after haemodialysis, and this may be accounted for by differences occurring in the calcium balance, both in the alimentary tract and in the dialysis system. This aspect is currently being investigated. Though it is not yet established whether changes in bone index truly represent total skeletal change, direct measurements of the mineral content of femoral bone have proved sufficiently sensitive to be used for monitoring patients on regular dialysis for renal disease. We suggest that this method gives additional information which is not provided by the present form of balance study. Furthermore, it can be applied to long-term assessment of therapy designed to restore calcium balance while the patient is living at home and undertaking normal activity.

\section{REFERENCES}

Curtis, J. R., et al. (1969). Quarterly fournal of Medicine, 38, 49.

Jowsey, J., Massry, S. G., Coburn, J. W., and Kleeman, C. R. (1969). Archives of Internal Medicine, 124, 539.

Kleeman, C. R., Massry, S. G., Coburn, J. W., and Popovtzer, M. M. (1969). Archives of Internal Medicine, 124, 262.

Moriarty, M. V., and Parsons, F. M. (1966). British fournal of Urology, 38,

623. W., West, R. R., and Atkinson, P. J. (1970). Proceedings of Symposium Ossium. In press. Sarnsethsiri, P., Jaworski, Z. F., Shimizu, A. G., and Frost, H. M. (1969).
Archives of Pathology, 88, 49 .

West, R. R., and Reed, G. W. (1970). In preparation.

\title{
Circulating Rheumatoid and Antinuclear Factors in Asbestos Workers
}

\author{
MARGARET TURNER-WARWICK, ${ }^{*}$ D.M., PH.D., F.R.C.P. ; W. RAYMOND PARKES, $\dagger$ M.D., M.R.C.P., D.I.H.
}

\begin{abstract}
Summary: In an unselected series of 80 patients with asbestos exposure referred to the London Pneumoconiosis Medical Panel, antinuclear and rheumatoid factors were found in 28 and $27 \%$ respectively. This probably represents at least a fourfold increase over their incidence in random populations. The presence of these autoantibodies was not related to the duration of exposure, but was related to the extent of radiographic abnormality.
\end{abstract}

\section{Introduction}

It has been shown (Turner-Warwick and Doniach, 1965) that there is an increased prevalence of antinuclear and rheumatoid factors in patients with the clinical syndrome of cryptogenic fibrosing alveolitis (idiopathic diffuse interstitial pulmonary fibrosis). Similarity between this syndrome and the clinical and pathological features seen in asbestosis suggested the possibility of circulating autoantibodies being found in persons with asbestosis. Pernis and Vigliani (1965) have reported an increased prevalence of rheumatoid factor in asbestos workers, especially those with abnormal chest radiographs; the overlap between asbestosis and "rheumatoid" diseases is further suggested by the rare occurrence of necrobiotic nodules in the lungs in asbestos workers (Rickards and Barrett, 1958; Tellesson, 1961; Morgan, 1964). We know of no published reports of circulating antinuclear factors in asbestosis. Studies of other pneumoconioses, especially that due to inhalation of coal dust, have already shown an association between certain radiographic features and the presence of both clinical rheumatoid arthritis and circulating rheumatoid factor (Caplan, 1953; Caplan et al., 1962; Lindars and Davies, 1967).

\section{Materials and Methods}

Subjects Studied.-Serum samples were collected from an unselected series of 80 people with a history of exposure to asbestos who were referred to the Pneumoconiosis Medical

\footnotetext{
* Consultant Physician, Brompton Hospital, London S.W.3, and London Chest Hospital, London E.2.

† Pneumoconiosis Medical Panel, London N.W.1.
}

Panel in London. These subjects were referred for a number of different reasons. Most commonly an abnormal chest radiograph was noted by the referring centre, either as a result of routine examination or because of respiratory symptoms. Less often patients were referred because abnormal signs suggestive of asbestosis-namely, finger-clubbing and persistent basal crepitations-had been observed. The patients studied therefore showed a range of clinical and radiographic features, and after assessment not all of them were accepted by the Panel as suffering from asbestosis.

Terminology.-Asbestosis is defined as widespread fibrosis of the lungs, particularly but not exclusively of the alveolar walls, attributed to inhaled asbestos dust. Lung tissue was of course not available to us, and for the purposes of this study the diagnostic criteria used to designate "asbestosis" were a history of exposure to asbestos dust and a radiograph showing bilateral irregular or small round shadows with or without honeycombing, and not obviously accounted for by other recognizable disease-for example, tuberculosis, sarcoidosis, heart disease. Additional supporting features included basal crepitations, clubbing of the fingers, and a restrictive ventilatory defect without airway obstruction, but these were not used as obligatory diagnostic criteria. At the present time there is no certain way of distinguishing the clinical syndrome of cryptogenic fibrosing alveolitis occurring by chance in an asbestos worker from asbestosis, and even lung biopsy may fail to resolve the problem in some cases.

Immunological Studies.-All the laboratory studies were completed without previous knowledge of the clinical and radiographic details of the subjects. Antinuclear factors (A.N.F.) were measured by a standard double-layer immunofluorescent technique with rat liver as substrate using antisera to human $\gamma$-globulin conjugated with fluorescein isothiocyanate (Coons and Kaplan, 1950) and test serum diluted 1:10. Antisera were conjugated with fluorescein isothiocyanate used $1: 50$ by weight to antisera of standard protein content $(10 \mathrm{mg} . / \mathrm{ml}$. giving a final $F / P$ ratio of $2: 1)$. Before use the conjugates were diluted 8 or 16 times to give maximum contrast between nuclear and background fluorescence without reducing the titre of known positive control sera. Test sera found to be positive at $1: 10$ were titrated by use of increasing dilutions in the immunofluorescent test. Titres of $1: 10$ and over were accepted as positive. The immunoglobulin class of A.N.F. was identified by the same 
immunofluorescent method, using conjugated monospecific antisera to $\operatorname{IgM}$ and $\operatorname{IgG}$, showing single precipitin lines on immunoelectrophoresis (obtained from the Blood Transfusion Service, Amsterdam) on serial dilutions of serum from $1: 2$. Rheumatoid (antiglobulin) factors were measured by standard techniques by means of sheep red cells coated with rabbit globulin in the differential agglutination test (D.A.T.) (Rose et al., 1948) and latex particles coated with human FII fraction (Singer and Plotz, 1956). A D.A.T. of $1: 16$ and over was accepted as positive. In the latex test serum was diluted $1: 20$.

Radiographic Analysis.-On completion of the immunological tests the chest radiographs were studied after referring to standard films classified in accordance with the new category system of the Union Internationale contre le Cancer (U.I.C.C./Cincinnati Classification of the Radiographic Appearances of the Pneumoconioses: to be published) and kindly supplied by the Pneumoconiosis Research Unit in South Wales. From this complex classification five main features were selected for analysis-namely, profusion of the pulmonary lesions graded from $0 / 0$ to $3 / 3$ (Liddell, 1963); coarseness of irregular opacities classed accurding to degree as $s, t$, or $u$; and size of small round lesions classed as $\mathrm{p}, \mathrm{q}$, or $\mathrm{r}$, corresponding to $\mathrm{p}, \mathrm{m}$, and $\mathrm{n}$ of the International Labour Office (1959) classification. The extent of pleural involvement was graded 1,2 , or 3 and the presence of honeycombing and other shadows noted.

\section{Results}

\section{Immunological}

Antinuclear or rheumatoid factors, or both, were detected in $38(47.5 \%)$ of the 80 patients: a weak positive latex FII test only was found in an additional five patients, but in view of the doubtful significance of a weak positive in this test they have been classed as negative reactors in the analyses. Antinuclear factors were found in 23 of 80 sera $(28.8 \%)$ and rheumatoid factors were found in the same sera in seven instances $(8.8 \%)$.

The titres and the immunoglobulin type of A.N.F. are set out in Fig. 1. Though only two sera showed titres of over

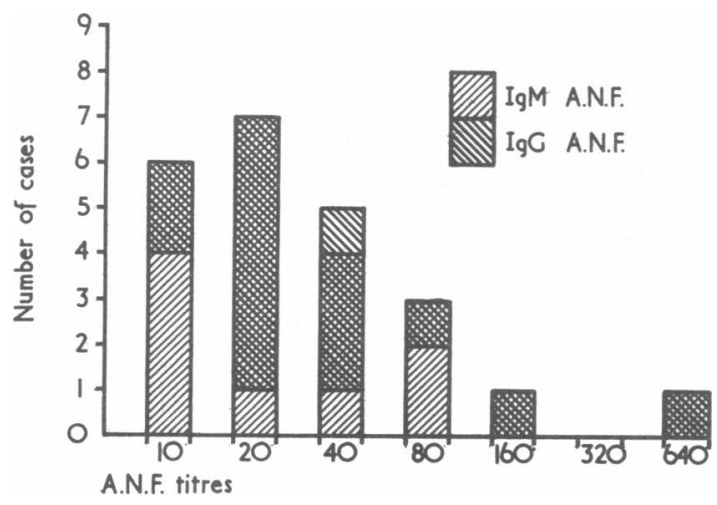

FIG 1.-Distribution of A.N.F. titres and Ig class of A.N.F. in 23 positive sera from asbestos workers. Titrations refer to A.N.F. present in dilutions of test serum using whole antihuman $\gamma$-globulin. Symbols show Ig class of A.N.F. for each serum but do not indicate individual immunoglobulin A.N.F. titres.

$1: 100,10$ of 23 positive sera had titres of $1: 40$ and greater. A.N.F. of IgM type was seen in eight, and of a mixed IgG and IgM type in 14 sera. In only 1 of 23 positive sera was IgG A.N.F. found alone. In sera showing both IgG and IgM type of A.N.F. the titres of IgG A.N.F. were usually lower than those for IgM and were less than 1:10 in all but four instances.

Titres of rheumatoid factors are set out in Fig. 2. Three patients showed a strongly positive latex test with negative

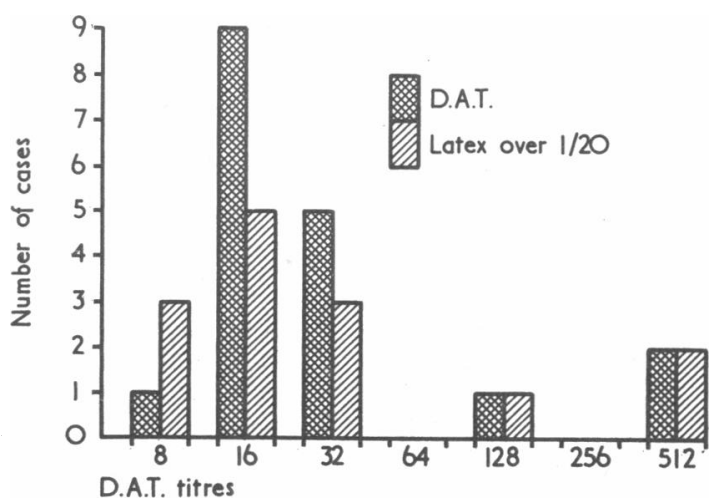

FIG 2.-Distribution of titres of rheumatoid factor in asbestos workers.

D.A.T. titres of $1: 8$ or less. Of 17 patients with positive D.A.T. titres of $1: 16$ or greater 11 also had positive latex tests of 1:20 or over. Polyarthritis was present in four of these 17 patients, and, in another, subcutaneous olecranon nodules were palpable in the absence of arthritis.

\section{Clinical}

Certain clinical and radiographic features were correlated with the groups of patients with and without circulating autoantibodies. The ages, sex, duration of exposure, and smoking habits are summarized in Table I, and both groups are shown to be similar.

TABLE I

\begin{tabular}{|c|c|c|}
\hline & With Antibodies & Without Antibodies \\
\hline $\begin{array}{lcc}\text { Age (years) } & . & \ldots \\
\text { Male/female } & . & \ldots\end{array}$ & Mean $55 \cdot \frac{1}{35 / 38}($ range $30-68)$ & $\begin{array}{c}\text { Mean } 53 \cdot 1 \text { (range } 31-68) \\
40 / 42\end{array}$ \\
\hline $\begin{array}{c}\text { Duration of asbestos ex- } \\
\text { posure (years)... }\end{array}$ & $\begin{array}{l}\text { Mean 18.1 (range 1-46) } \\
\text { Smokers }\end{array}$ & Mean 20.7 (range 2-45) \\
\hline Smoking . . & $\left.\begin{array}{l}\text { Ex-smokers } 11 \\
\text { Non-smokers } 4\end{array}\right\} 34$ & $\left\{\begin{array}{l}14 \\
3\end{array}\right\} 39$ \\
\hline
\end{tabular}

The presence of obvious finger-clubbing and persisten basal crepitations on auscultation is shown in Table II. All doubtful signs have been regarded as negative. It appears that tissue antibodies are found more often in those with both clubbing and crepitations.

TABLE II.-Antibodies and Physical Signs

\begin{tabular}{|c|c|c|c|c|}
\hline & & & Antibodies & No Antibodies \\
\hline \multirow[t]{2}{*}{$\begin{array}{l}\text { Clubbing only } \ldots \\
\text { Crepitations only } \\
\text { Clubbing and crepitations } \\
\text { Neither } \ldots\end{array}$} & $\begin{array}{l}\cdots \\
\cdots \\
\cdots\end{array}$ & $\begin{array}{l}\ldots \\
\cdots \\
\cdots\end{array}$ & $\left.\begin{array}{r}1 \\
15 \\
14 \\
8\end{array}\right\} 0$ & $>0.001\left\{\begin{array}{r}3 \\
12 \\
5 \\
22\end{array}\right.$ \\
\hline & Total & . & 38 & 42 \\
\hline
\end{tabular}

More severe radiographic shadowing is related significantly to the presence of antibodies (Table III), and this is reflected in an analysis of both the profusion and the coarseness of radiographic shadows. Nevertheless, coarse and extensive radiographic shadows were seen in some patients without circulating antibodies, and honeycombing was seen with equal frequency in both groups.

TABLE III.-Antibodies and Radiographic Appearances

\begin{tabular}{|c|c|c|c|c|c|c|}
\hline \multirow{2}{*}{\multicolumn{5}{|c|}{ Total }} & Antibodies & No Antibodies \\
\hline & & & & & 38 & 42 \\
\hline Profusion & $\left\{\begin{array}{l}0-1 \\
2-3\end{array}\right.$ & . & $\cdots$ & $\cdots$ & \multicolumn{2}{|c|}{$\left.\begin{array}{r}8 \\
30\end{array}\right\} 0.02>P>0.01\left\{\begin{array}{l}20 \\
22\end{array}\right.$} \\
\hline Coarseness & $\left\{\begin{array}{r}0-s \\
t-u \\
q\end{array}\right.$ & $\because$ & $\begin{array}{l}\cdots \\
\cdots\end{array}$ & $\begin{array}{l}\cdots \\
\cdots \\
\cdots\end{array}$ & \multicolumn{2}{|c|}{$\underset{6}{11}\}$ o.02 $>P>0.01\left\{\begin{array}{l}26 \\
16 \\
0\end{array}\right.$} \\
\hline Pleural & $\left\{\begin{array}{l}0-1 \\
2-3\end{array}\right.$ & $\begin{array}{l}\cdots \\
\cdots\end{array}$ & $\begin{array}{l}. \\
\cdots\end{array}$ & $\cdots$ & \multicolumn{2}{|c|}{$\left.\begin{array}{l}24 \\
14\end{array}\right\} 0.10>P>0.05\left\{\begin{array}{r}34 \\
8\end{array}\right.$} \\
\hline
\end{tabular}


There were 12 radiographs with virtually no pleural (grade $0 / 1$ ) or pulmonary (grade $0 / 1$ ) shadowing, and serum from only one of these contained antibodies, whereas 37 of 68 patients (54\%) with definite radiographic abnormality of the types indicated above were shown to have either antinuclear or rheumatoid factors or both. In a control series of 113 sera from asbestos workers of similar sex, age (mean 55.3 years), and duration of exposure (mean 14.6 years) but with normal chest radiographs, only three $(2.6 \%)$ showed A.N.F. in our standard immunofluorescent test.

A preliminary attempt was made to identify "active" pulmonary disease in terms of observed radiographic progression (Figs. 3 and 4) in patients followed for five years up to the time of study. Nineteen such patients were available. Of the six patients with circulating antibodies all showed progressive

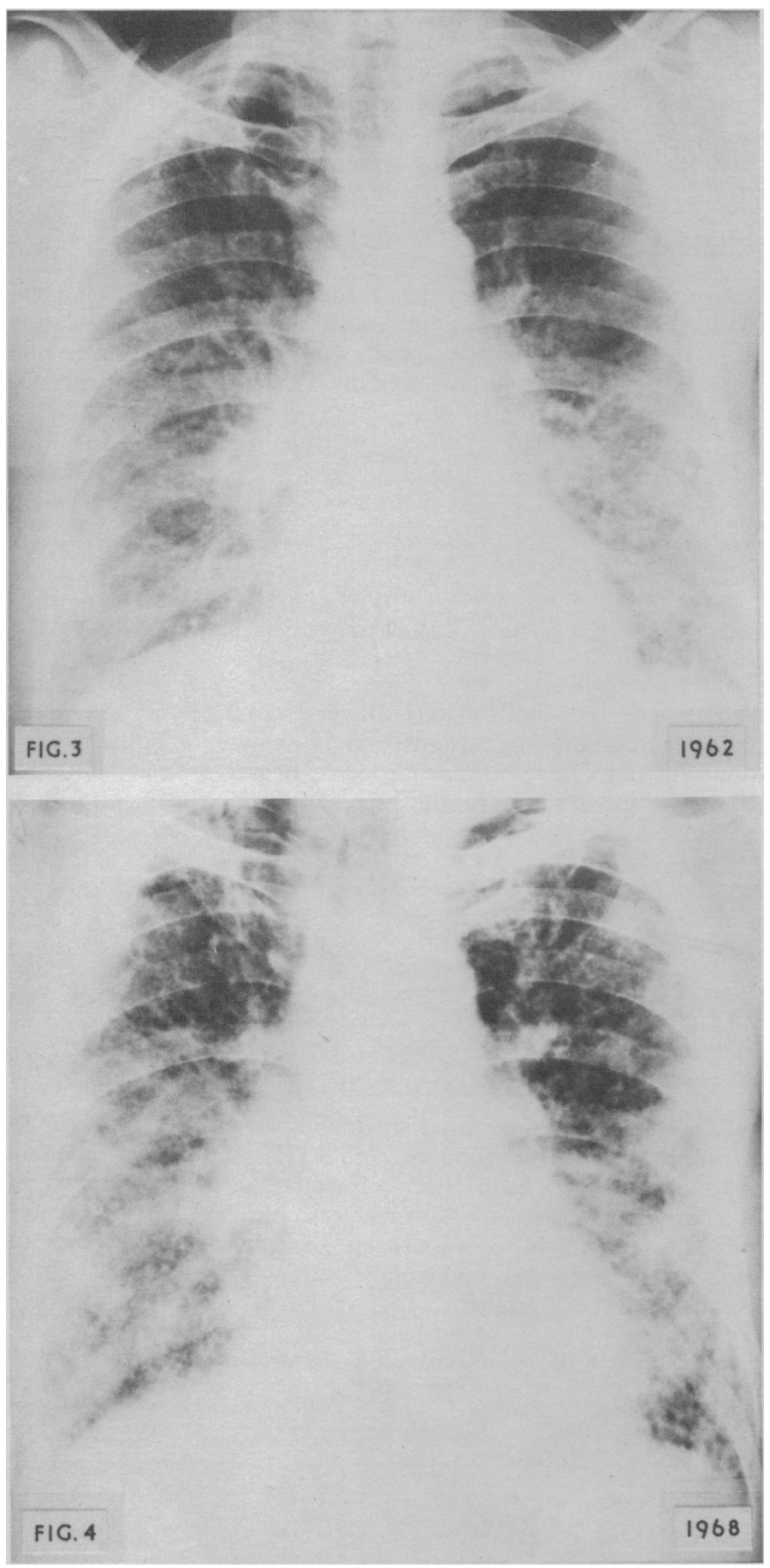

FIGs. 3 and 4 show progression of asbestosis over 5 -year period 1962-8. Man aged 66 in 1968. Asbestos exposure 11 years. No clinical theur
arthritis. A.N.F. negative. D.A.T. 1 :128. Latex positive. disease, while of 13 without tissue antibodies only four showed evidence of radiographic progression.

\section{Discussion}

The prevalence of both antinuclear and rheumatoid factors in this series is at least four times greater than has been found in random populations of this age group. Antinuclear factors in titres of $1: 10$ and over has been found in about $5 \%$ of subjects in a large number of control groups which included men and women: and titres of $1: 16$ and over in men over 40 years old in less than $2 \%$ (Beck, 1963). Rheumatoid factors have also been found in about $5 \%$ of random populations of men and women (Ball and Lawrence, 1961), in comparison with the incidence of our series of $27 \%$. The titres of antinuclear factors observed in our cases were lower than those in typical systemic lupus erythematosus, where titres are often in excess of 1:200; but they do show a distribution similar to the titres in cryptogenic fibrosing alveolitis, where titres of 1:50 and over were found in $30 \%$ of positive sera (Turner-Warwick, unpublished).

Antinuclear factor found in "autoimmune" disease may belong to various immunoglobulin classes, and A.N.F. activity can often be identified in more than one Ig class within the same serum (Barnett et al., 1965). In systemic lupus erythematosus IgG A.N.F. often predominates, whereas in other connective tissue disorders, such as rheumatoid arthritis, Sjögren's syndrome, and systemic sclerosis, an IgM type of A.N.F. is often found (Holborow and Johnson, 1965). In common with these connective-tissue disorders our asbestosis sera showed a predominantly IgM type of A.N.F.

The presence of rheumatoid factor in our series confirms the findings of Pernis and Vigliani (1965) and shows that the small irregular type of radiographic appearances in asbestosis can be associated with circulating antiglobulin factors of similar types as have been described in association with the nodular appearance seen in the pneumoconiosis of coal miners (Caplan et al., 1962). A range of lung changes associated with circulating rheumatoid factor is now beginning to emerge. In patients with seropositive rheumatoid arthritis without industrial dust exposure, two types of pathological change are seen in the lung-namely, diffuse interstitial fibrosis (radiographically characterized by small irregular opacities, especially at the lung bases) and necrobiotic nodules (seen on radiographs as $1-3 \mathrm{~cm}$. round shadows). Both of these are sometimes observed in seropositive patients without clinical rheumatoid arthritis. In asbestosis both types of lung lesion are seen, and circulating rheumatoid factor has now been demonstrated in about a quarter of these cases, associated with polyarthritis in four instances.

Large necrobiotic pulmonary nodules are probably very rare in asbestos workers but are well recognized in coal miners with and without rheumatoid arthritis (Caplan et al., 1962). Micronodular opacities $(0.3$ to $1 \mathrm{~cm}$. diameter) in coal miners are also associated with circulating rheumatoid factors, again in those with and without arthritis. Similar micronodular lesions have been described in asbestosis (Nice and Ostrolenk, 1968; Solomon, 1969), and were seen in six of our cases-in three instances associated with circulating rheumatoid factor. Diffuse interstitial fibrosis (often with honeycombing) is also seen occasionally in coal miners' lungs with or without coal pneumoconiosis, again in association with circulating rheumatoid factor. Though there is no direct evidence to prove that this is more than a fortuitous association, the observation is of particular interest in the context of the foregoing discussion.

The stimulus to the formation of antinuclear and rheumatoid factors and their role in pathogenesis remains unknown, but some information can be obtained from the data presented here. Tissue antibodies are not related to the duration of exposure to asbestos, but they do appear to correlate 
with the more severe and, possibly, progressive lung changes. This suggests the possibility that the presence of antibodies is either related in some indirect way to pathogenesis or results from tissue damage. On the other hand, the presence of quite severe lung changes without antibodies suggests that they are neither directly responsible for the lung changes nor are they likely to result non-specifically from lung destruction. The absence of A.N.F. and rheumatoid factor in many other types of chronic fibrosing lung disease, including chronic farmer's lung, chronic bird-breeder's lung, and sarcoidosis (TurnerWarwick and Haslam, unpublished), is supporting evidence that these autoantibodies do not occur as a result of lung damage alone.

Possibly circulating antibody and cellular hypersensitivity together initiate lung damage analogous to experimental allergic orchitis (Holborow and Johnson, 1965); this is now being investigated. Alternatively, circulating autoantibodies may in some other way enhance tissue damage caused by asbestos dust. Another explanation for the increased prevalence of circulating antibodies is that, for some reason at present unknown those members of the general population with a genetic tendency to produce antiglobulin and antinuclear factors may react in an abnormal way to inhalation of asbestos or to the inflammatory response it provokes, and are therefore selected out into the group of exposed subjects developing lung changes. A further survey is now in progress to study the incidence of tissue antibodies in large numbers of asbestos workers with and without evidence of lung disease. A similar selection process has been suggested to account for the increased prevalence of rheumatoid factor in certain categories of coal miners' pneumoconiosis (Lindars and Davies, 1967). If this theory proves correct then screening for circulating antinuclear and antiglobulin factors before acceptance into any industry with an asbestos hazard might form a basis for excluding from risk those with unusual susceptibility.

We should like to thank Mrs. Haslam and Mrs. Weeks for technical assistance, and Mrs. N. Murray for her help with co-ordination of the study. We are also grateful to the Asbestos Research Council, the Chest and Heart Association, and the Medical Research Council for their generous support; and to Dr. J. Watkins Pitchford, chief medical officer in the Department of Health and Social Security, for permission to publish. We should also like to thank Dr. A. Caplan for his interest in the work.

\section{REFERENCES}

Ball J., and Lawrence, J. S. (1961). Annals of the Rheumatic Diseases, 20, 235. Barnett, E. V., Leddy, J. P., Condemi, J. J., and Vaughan, J. H. (1965). Annals of the New York Academy of Sciences, 124, 896.

Beck, J. S. (1963). Scottish Medical fournal, 8, 373.

Brown, P. C., Glynn, L. E., and Holborow, E. J. (1967). Immunology, 13, 307 Brown, P. C., Glynn, L. E., and Holt

Caplan, A., Payne, R. B., and Withey, J. L. (1962). Thorax, 17, 205.

Coons, A. H., and Kaplan, M. H. (1950). Fournal of Experimental Medicine, 91, 1 .

Holborow, E. J., and Johnson, G. D. (1965). Annals of the New York Academy of Sciences, 124, 833.

International Labour Office (1959). Occupational Safety and Health 9, 2.

Liddell, F. D. K. (1963). British Fournal of Industrial Medicine, 20, 300.

Lindars, D. C., and Davies, D. (1967). Thorax, 22, 525.

Morgan, W. K. C. (1964). Thorax, 19, 433.

Nice, C. M., and Ostrolenk, D. G. (1968). Diseases of the Chest, 54, 226 Pernis, B., and Vigliani, E. C. (1965). Annals of the New York Academy of Sciences, 132, 112

Rickards, A. G., and Barrett, G. M. (1958). Thorax, 13, 185.

Rose, H. M., Ragan, C., Pearce, E., and Lipman, M. O. (1948). Proceedings of the Society of Experimental Biology and Medicine, 68, 1 .

Singer, J. M., and Plotz, C. M. (1956). American fournal of Medicine, 21, 888. Solomon, A. (1969). South African Medical fournal, 43, 847

Tellesson, W. B. (1961). Thorax, 16, 372.

Turner-Warwick, M., and Doniach, D. (1965). British Medical fournal, 1, 886 .

\title{
Sulphadimidine Acetylation Test for Classification of Patients as Slow or Rapid Inactivators of Isoniazid
}

\author{
K. V. N. RAO,* D.SC. ; D. A. MITCHISON†, M.B., M.R.C.P., M.R.C.PATH. ; N. G. K. NAIR, $\ddagger$ M.SC. \\ K. PREMA, $\$ M.SC. ; S. P. TRIPATHY, $\|$ M.D.
}

British Medical fournal, 1970, 3, 495-497

\begin{abstract}
Cummary: Sulphadimidine acetylation studies were un$S$ dertaken in 103 patients, 52 of whom had been classified as slow and 51 as rapid inactivators of isoniazid by a standard microbiological assay method. Each patient received sulphadimidine by mouth in a dose of 44 $\mathrm{mg} / \mathrm{kg}$. body weight, and free and total sulphadimidine were estimated in blood and urine collected at six hours. The findings suggest that patients may be classified as slow inactivators of isoniazid if the proportion of acetylated sulphadimidine (total minus free) is (a) less than $25 \%$ in blood or (b) less than $70 \%$ in urine. The sulphadimidine test is easy to perform and the result is available the same day; urine specimens for the test can be stored at room temperature for over a week without any loss of drug.
\end{abstract}

- Formerly Senior Research Officer (Biochemistry), Tuberculosis Chemotherapy Centre, Madras 31. Present address: W-615, Department of Medicine, University of Chicago, Chicago, Ill., U.S.A

† Director, M.R.C. Unit for Laboratory Studies of Tuberculosis, and Professor of Bacteriology, Royal Postgraduate Medical School, London W.12.

\# Assistant Research Officer (Statistics), Tuberculosis Chemotherapy Centre, Madras 31.

$\checkmark$ Assistant Research Officer (Biochemistry), Tuberculosis Chemotherapy Centre, Madras 31.

|| Director, Tuberculosis Chemotherapy Centre, Madras 31.

\section{Introduction}

Several investigators have shown that the rate of inactivation of isoniazid depends on the rate of its acetylation (Evans and White, 1964; Peters, Miller, and Brown, 1965), and that individuals can be broadly classified as slow or rapid inactivators (Knight, Selin, and Harris, 1959; Evans, Manley, and McKusick, 1960; Jenne, 1960; Sunahara, Urano, and Ogawa, 1961). Until recently the determination of the rate of inactivation had little practical value in the chemotherapy of pulmonary tuberculosis, since the rate was of little or no prognostic importance with daily regimens (Harris, 1959, 1961; Selkon et al., 1961; Schmidt, 1962; Scottish Thoracic Society, 1962; Tuberculosis Chemotherapy Centre, Madras, 1963). With the advent of intermittent regimens, however, the determination of the isoniazid inactivation rate acquired much practical importance. For instance, a recent study from this centre showed that the response of rapid inactivators of isoniazid to once-weekly regimens of chemotherapy is substantially inferior to that of slow inactivators (Menon, 1968; Tuberculosis Chemotherapy Ventre, Madras, 1970).

The rate of inactivation of isoniazid is usually determined by estimating the concentration of free isoniazid in the serum (by microbiological or chemical methods) at a specified time after a test dose of the drug. However, the need for collecting 